\title{
Anka Muhlstein, Napoléon à Moscou
}

\section{Annie Crépin}

\section{OpenEdition}

\section{Journals}

Édition électronique

URL : https://journals.openedition.org/ahrf/10792

DOI : 10.4000/ahrf.10792

ISSN : 1952-403X

Éditeur :

Armand Colin, Société des études robespierristes

Édition imprimée

Date de publication : 1 janvier 2009

Pagination : 242-243

ISBN : 978-2-200-92557-4

ISSN : 0003-4436

Référence électronique

Annie Crépin, «Anka Muhlstein, Napoléon à Moscou », Annales historiques de la Révolution française [En ligne], 355 | janvier-mars 2009, mis en ligne le 01 décembre 2009, consulté le 23 avril 2022. URL : http://journals.openedition.org/ahrf/10792 ; DOI : https://doi.org/10.4000/ahrf.10792

Ce document a été généré automatiquement le 23 avril 2022

Tous droits réservés 


\title{
Anka Muhlstein, Napoléon à Moscou
}

\author{
Annie Crépin
}

\section{RÉFÉRENCE}

Anka Muhlstein, Napoléon à Moscou, Paris, Odile Jacob, 2007, 305 p., ISBN

978-2-7381-1989-6, $23 €$.

1 Dans l'avant-propos de son ouvrage, Anka Muhlstein en explicite les buts : elle voulait se livrer à une investigation sur l'attitude de Napoléon pendant la désastreuse campagne de Russie et tenter de percer à jour ses atermoiements qui paraissent quelque peu en contradiction avec la lucidité et l'esprit de décision dont il avait fait preuve jusque là; elle souhaitait aussi démontrer son étonnante capacité de rebondissement au cours de la retraite qui, selon elle, ne semble une inéluctable défaite que dans une vision rétrospective.

2 L'essentiel de l'ouvrage est donc une narration de la campagne et s'appuie presqu'exclusivement sur les mémoires des contemporains (bien que certains aient été rédigés fort longtemps après l'événement). Les différents épisodes de la lutte, les combats puis la «dérobade » de l'armée russe et «la fuite en avant » de l'armée de Napoléon, la prise de Moscou, enfin l'interminable maintien de la Grande Armée dans la ville dévastée et incendiée, scandent ce livre qui se compose de douze chapitres écrits dans un style alerte et vivant. La retraite elle-même qui n'est pas ici traitée comme épisode central ne fait l'objet que d'un chapitre. Très factuelles, ces pages ne sont pas seulement centrées sur la psychologie de l'empereur mais aussi et surtout sur les conditions de vie - et de mort - des protagonistes, qu'ils soient soldats de Napoléon, combattants de l'armée adverse ou paysans russes.

Elles sont parsemées de détails concrets et terre-à-terre, que Napoléon eut parfois le tort de négliger: par exemple le progrès que représentent pour les fantassins les chaussures par rapport aux bottes, la soif - ou au contraire un abreuvement excessif qui décime les chevaux. L'auteure brosse de très beaux ou de très saisissants tableaux : on retiendra tout particulièrement le «spectacle " qui s'offre aux yeux des troupes 
quand elles pénètrent dans Smolensk, le champ de bataille de la Moskova (Borodino), l'arrivée à Moscou et surtout le saccage de la ville par la Grande Armée sur fond d'incendie qui transforme l'atmosphère de la cité en un tragique carnaval et un hallucinant «bal des maudits». Avec beaucoup de finesse, Anka Muhlstein décrit l'impasse stratégique et diplomatique dans laquelle l'empereur s'enferme à Moscou et surtout son refus de l'admettre, et par conséquent de préparer la retraite ce qui la transformera en déroute. On peut par contre trouver plus contestables ses affirmations sur l'aspect totalement inédit qu'aurait revêtu cette guerre aux yeux de Napoléon, l'empêchant d'user de son génie manœuvrier comme il l'avait fait sur d'autres terrains, et sur le caractère de conquête barbare qu'elle aurait représenté. Certaines campagnes précédentes n'avaient-elles pas présenté les prémices de ces traits?

4 À ce récit très vivant qui ne se veut pas une thèse universitaire, on ne reprochera certes pas de ne pas suivre l'approche historiographique mise en valeur par la nouvelle histoire militaire et fondée sur l'histoire culturelle de la guerre, bien que certains passages soient des éléments de tout premier plan pour cette approche.

5 Mais, même si le tableau de l'état des forces en présence est esquissé au cours du premier chapitre, on regrettera que la contextualisation de cette narration de la campagne de Russie ne soit pas plus approfondie. Au demeurant, dans la bibliographie, ne sont pas cités des ouvrages généraux sur la période, tels ceux de Thierry Lentz ou de Jean-Paul Bertaud. On regrettera encore qu'aucun recul critique ne soit pris par rapport aux sources utilisées, aucune appréciation du fait que la mémoire ait pu transformer ou déformer les perceptions des auteurs de mémoires. Il aurait été bienvenu à cet égard de citer les travaux de Nathalie Petiteau et d'Alan Forrest sur des thèmes voisins ou proches. L'index biographique, certes bienvenu, cède parfois à l'anecdote. 